\title{
Transdiaphragmatic pressure in quadriplegic individuals ventilated by diaphragmatic pacemaker
}

Honesto Garrido-García, Pedro Martín-Escribano, Jesús Palomera-Frade, Olga Arroyo, José L Alonso-Calderón, Jesús Mazaira-Alvarez

\begin{abstract}
Background - Electrophrenic pacing can be used in the management of ventilatory failure in quadriplegic patients. A study was undertaken to determine the pattern of transdiaphragmatic pressure (PDI) during the conditioning phase of electrophrenic pacing to see if it had a possible role in optimising the process of conditioning.

Methods - The tidal volume (TV) and PDI were measured in a group of six quadriplegic patients commencing ventilation by low frequency pulse stimulation $(7-10 \mathrm{~Hz})$ and low respiratory rate stimulation ( $<10$ breaths/min).

Results - Tidal volume increased between baseline and month $1(4.33 \mathrm{ml} / \mathrm{kg}, \mathrm{p}<0.001)$ and between months 1 and $2(3.00 \mathrm{ml} / \mathrm{kg}$, $p<0.05)$ and then stabilised. PDI was higher during bilateral diaphragmatic pacing (mean (SD) $1.73(0.30) \mathrm{kPa}$ ) than with either left $(1.15(0.34) \mathrm{kPa})$ or right $(0.86$ $(0 \cdot 37) \mathrm{kPa})$ unilateral pacing. PDI varied throughout the observation period, probably by interaction between recovery of the diaphragmatic fibres and the pacing regimen.

Conclusions - Patients with quadriplegia due to high spinal injury can be maintained with ventilation by continuous electrophrenic pacing. The control criteria used in this study for pacing were tidal volume and the patient's tolerance, and the PDI measurement did not contribute any additional information to help with managing the conditioning process.

(Thorax 1996;51:420-423)
\end{abstract}

Keywords: diaphragmatic pacemaker, electrophrenic ventilation, quadriplegics, transdiaphragmatic pressure.

Pneumology

Department, Hospital

12 de Octubre, 28041

Madrid, Spain

P Martín-Escribano

J Palomera-Frade

National Hospital for Paraplegics, Toledo, Spain

J Mazaira-Alvarez

Correspondence to: Dr P Martín-Escribano.

Received 28 September

1994
Returned to authors

11 January 1995

11 January 1995

20 July 1995

Accepted for publication

23 November 1995 for quality of life of patients, making it possible electrophrenic pacing is started there is a period of conditioning of the diaphragm as it recuperates. $^{6}$ We have measured the transdiaphragmatic pressure (PDI) during this
Patients with quadriplegia due to high medimplanted electrophrenic pacemaker. The use of a stable diaphragmatic pacemaker in lieu of mechanical ventilation substantially improves conditioning period in quadriplegic patients at the commencement of electrophrenic pacing and during their later follow up to determine if PDI has a role in optimising the conditioning process.

\section{Methods}

Six patients with quadriplegia due to accidental traumatic spinal injury at the $\mathrm{C} 1-\mathrm{C} 2$ level who were being started on ventilation by electrophrenic pacing were studied. The criteria for implantation were (1) chronic respiratory failure requiring artificial ventilation via a tracheostomy, (2) acceptable pulmonary function assessed clinically and by radiology, (3) normal arterial gases while mechanically ventilated on air, (4) normal level of consciousness, and (5) normal intrathoracic phrenic nerve conduction (that is, between 4 and $12 \mathrm{~ms}$ ). ${ }^{78}$ The diaphragmatic response to electrical stimulation was evaluated by assessing diaphragmatic mobility on fluoroscopy or echography and by electromyography of the diaphragmatic action potentials evoked by supramaximal electrostimulation of the phrenic nerve; the normal range of this measurement is very wide $(80-1500 \mu \mathrm{V}) .^{9}$

Two types of pacemaker were used: two patients received the S232 Avery (Farmingdale, New York) and four patients the Atrostim (Atrotech, Finland). The Avery pacemaker is monopolar and stimulates at $110 \mathrm{~ms}$ intervals and the Atrostim delivers multipolar stimulation at $160 \mathrm{~ms}$ intervals. ${ }^{10}$ Both systems are equipped with an external transmitter with antennae, an internal receptor, and electrodes. By means of the external transmitter, the amplitude, slope, or gradual pulse variation of the electrical stimulus can be modified, as can the respiratory rate, inspiration time, and pulse interval. The pulse interval is fixed in the Atrostim model. In every case the pacemaker was implanted using a thoracic approach and the surgical technique described by Glenn. ${ }^{1}$

Diaphragm conditioning consisted of a progressive increase in the duration of pacing until exclusive pacemaker ventilation was attained. The conditioning period can be carried out by alternating mechanical ventilation with diaphragmatic pacing. ${ }^{11}$ In this series the duration of diaphragmatic pacing was increased gradually. Beginning two weeks after pacemaker implantation, the patient was paced bilaterally for 10-20 minutes every hour during the daylight hours at a respiratory rate of 15 breaths/ 
Table 1 Characteristics of patients

\begin{tabular}{|c|c|c|c|c|c|c|}
\hline & \multicolumn{6}{|c|}{ Patient no. } \\
\hline & 1 & 2 & 3 & 4 & 5 & 6 \\
\hline Age (years) & 3 & 3 & 16 & 25 & 17 & 17 \\
\hline Sex & $\mathrm{M}$ & $\mathbf{M}$ & $\mathbf{M}$ & $M$ & $\mathrm{M}$ & $\mathrm{M}$ \\
\hline Weight $(\mathrm{kg})$ & 14 & 14 & 37 & 64 & 57 & 65 \\
\hline Height $(\mathrm{m})$ & $1 \cdot 27$ & 1.29 & $1 \cdot 60$ & $1 \cdot 64$ & 1.68 & $1 \cdot 80$ \\
\hline \multicolumn{7}{|c|}{ Conduction time (ms) } \\
\hline Right & $4 \cdot 5$ & $6 \cdot 5$ & $6 \cdot 5$ & $8 \cdot 5$ & $8 \cdot 0$ & $11 \cdot 0$ \\
\hline Left & $4 \cdot 5$ & $6 \cdot 5$ & $7 \cdot 0$ & $8 \cdot 5$ & $8 \cdot 0$ & $6 \cdot 0$ \\
\hline \multicolumn{7}{|c|}{ Action potential (mV) } \\
\hline Right & 650 & 500 & 800 & 500 & 750 & 850 \\
\hline Left & 700 & 650 & 650 & 750 & 750 & 750 \\
\hline Pacemaker & $\mathrm{AV}$ & AV & AT & AT & AT & AT \\
\hline Time (months) & 8 & 12 & 15 & 3 & 5 & 25 \\
\hline
\end{tabular}

$\mathrm{AV}=$ Avery pacemaker; $\mathrm{AT}=$ Atrostim pacemaker; time $=$ interval between accident causing quadri plegia and pacemaker implantation. min and at a pulse interval of $90 \mathrm{~ms}$ with the Avery model or $160 \mathrm{~ms}$ with the Atrostim model. ${ }^{12}$ Impulse duration ranged from 0.5 to $1.3 \mathrm{~s}$ and the intensity of the current applied to each electrode configuration was just enough to elicit submaximal tidal volumes, as measured by spirometry. The pacing time was increased weekly until $30 \mathrm{~min} /$ hour was reached, after which pacing periods were programmed for additional increases followed by resting periods of mechanical ventilation of the same duration until the patient could be paced for 12 hours without signs of diaphragmatic fatigue. Resting periods during sleep were then reduced progressively until permanent pacemaker ventilation without need for mechanical ventilation was attained. As permanent pacing was established, the frequency of stimulation pulses was reduced to $7-10 \mathrm{~Hz}$ in the Avery model. The respiratory rate, which began at 15 breaths/ min, was reduced to less than 10 as ventilation permitted. At the end of the conditioning period the tracheostomy cannula was replaced with a Teflon tube with a stopper that some patients removed during sleep.

Throughout the conditioning period we attempted gradually to reach an ideal pattern of stable exclusive pacemaker stimulation with the following characteristics: adequate tidal volume (TV) for the patient's morphometric characteristics $(15-20 \mathrm{ml} / \mathrm{kg}),{ }^{13}$ low respiratory rate (below 10 beats $/ \mathrm{min}$ ), low stimulation pulse frequency $(7-10 \mathrm{~Hz})$, and absence of conditions suggesting muscular fatigue such as progressive reduction of TV during pacing or poor patient tolerance. The guiding criteria were progressive increase of a stable TV and patient tolerance of the pacing and ventilatory regimen.

The pacemaker indication was established after assessing pulmonary function by measuring TV and arterial blood gases. During the conditioning period TV was measured by connecting a cannula fitted with an inflatable cuff to the tracheostomy present in all patients. An Ohmeda 5410 spirometer was used to measure digitally the TV, respiratory rate, and minute volume. These measurements were made at the end of every daily stimulation period during the conditioning period and were used as a guide for pacing adjustments. All measurements were made in the same position for each patient.
PDI was determined using polyethylene balloon catheters and the technique described by Agostoni et al $^{14}$ and Roussos and Macklem ${ }^{15}$; the catheters were inserted through the nose and the balloon was inflated with 2 or $3 \mathrm{ml}$ of air, a volume that provides very sensitive tracings. Successive pressure measurements were made in the lower third of the oesophagus, in the stomach, and again in the oesophagus using a Jaeger Pneumotest Bodytest device. The stability of the oesophageal pressure before and after measurement of the gastric pressure was confirmed by excluding oesophageal contractions or abdominal muscle spasms. Pressures were measured during bilateral diaphragmatic pacing and with individual left and right hemidiaphragmatic pacing. During bilateral diaphragmatic pacing the tracing was recorded for two minutes or longer if the tracing was not very stable. Patients were less tolerant of unilateral diaphragmatic pacing so the tracing was recorded for a shorter time period, although at least three respiratory cycles were always included. No attempt was made to mcasure the patient's tolerance of unilateral pacing, but the patient quickly (15-30 s) felt the change from bilateral to unilateral pacing. The measurements were always made at noon during diaphragmatically paced ventilation. During the conditioning period patients were ventilated diaphragmatically for at least three hours before measurements were made. Manometric studies were made at varying intervals, depending on the conditions of care, starting two months after pacemaker implantation.

\section{Results}

The six patients were consecutive in a series of patients who had undergone electrophrenic pacemaker implantation since 1989. All were men and achieved permanent simultaneous bilateral ventilation by diaphragmatic pacing and could forego mechanical ventilation, reside at home, and go out with a specially equipped wheelchair. Table 1 shows details of the six patients. A good correlation was found between the subject's height and phrenic nerve conduction time on the right side (Pearson correlation $r=0.85, \mathrm{p}<0.05)$ but not on the left $(r=0 \cdot 54, \mathrm{p}=\mathrm{NS})$.

The conditioning period lasted about three months in the adults and four months in the children. The evolution of TV in the first five months is shown in fig 1 . There was a significant increase in mean TV between baseline and month $1(4.33 \mathrm{ml} / \mathrm{kg}, \mathrm{p}<0.001,95 \%$ confidence interval (CI) 6.05 to 2.62 ) and between months 1 and $2(3.00 \mathrm{ml} / \mathrm{kg}, \mathrm{p}<0.05,95 \%$ CI 5.48 to 0.52 ) with no significant change thereafter. The two largest increases in TV were seen in the two babies.

The mean (SD) PDI elicited by bilateral stimulation $(1.73(0.30) \mathrm{kPa})$ was, for the whole group, significantly greater $(\mathrm{p}<0.001)$ than that achieved by unilateral stimulation of either hemidiaphragm, with the PDI achieved by left hemidiaphragmatic stimulation $(1 \cdot 15(0.34) \mathrm{kPa})$ being significantly greater $(p<0 \cdot 01)$ than that 


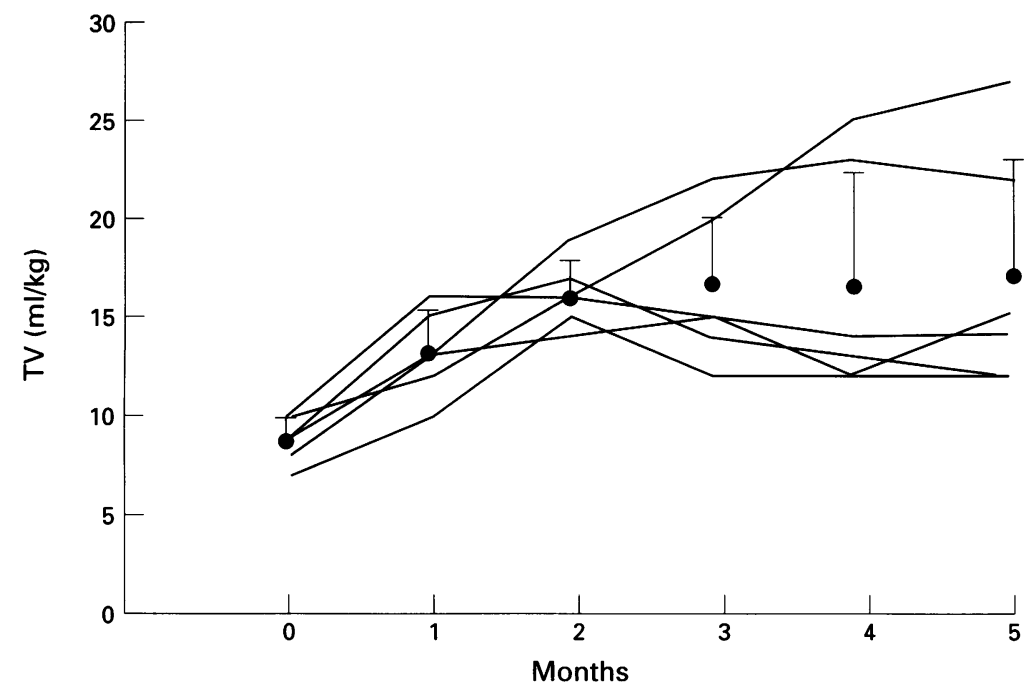

Figure 1 Evolution of tidal volume (TV, ml BTPS/kg) in six patients measured monthly throughout the diaphragmatic conditioning period.

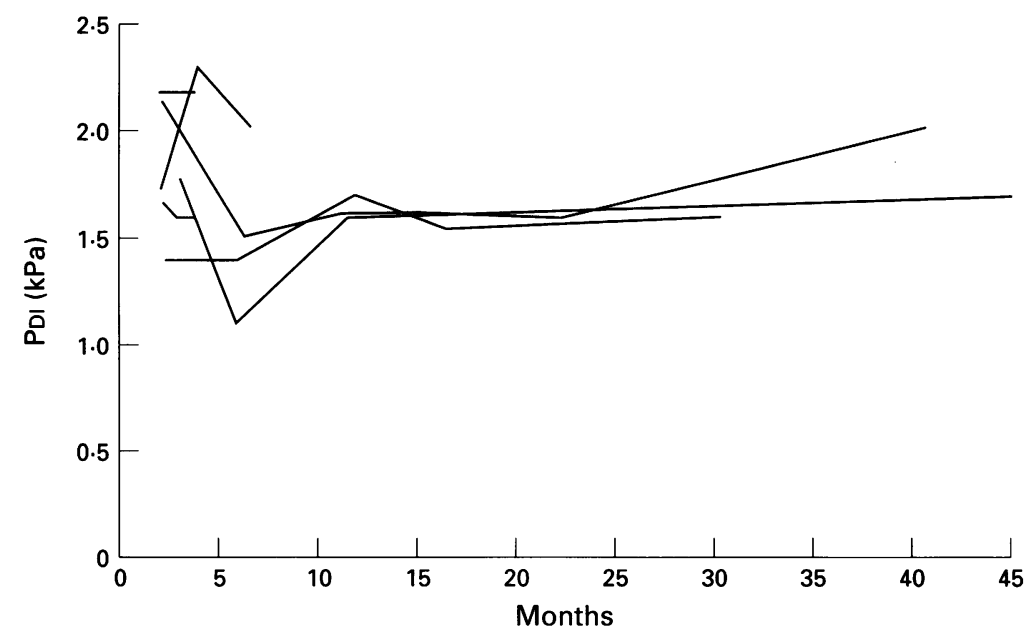

Figure 2 Transdiaphragmatic pressure (PDI, $\mathrm{kPa}$ ) throughout the conditioning and follow up periods.

Table 2 Functional characteristics of the patients at the last follow up while breathing room air with pacemaker control

\begin{tabular}{llllll}
\hline Patient no. & $\begin{array}{l}f \\
\text { (breaths/min) }\end{array}$ & $\begin{array}{l}T V \\
(\mathrm{ml} / \mathrm{kg})\end{array}$ & $p H$ & $\begin{array}{l}\mathrm{PaCO}_{2} \\
(\mathrm{kPa})\end{array}$ & $\begin{array}{l}\mathrm{PaO}_{2} \\
(\mathrm{kPa})\end{array}$ \\
\hline 1 & 10 & $30 \cdot 7$ & $7 \cdot 35$ & $5 \cdot 2$ & $11 \cdot 6$ \\
2 & 10 & $24 \cdot 6$ & $7 \cdot 36$ & $4 \cdot 8$ & $12 \cdot 0$ \\
3 & 10 & $12 \cdot 5$ & $7 \cdot 39$ & $5 \cdot 6$ & $11 \cdot 2$ \\
4 & 8 & $15 \cdot 6$ & $7 \cdot 42$ & $4 \cdot 7$ & $12 \cdot 0$ \\
5 & 8 & 10.7 & $7 \cdot 41$ & $4 \cdot 8$ & $12 \cdot 3$ \\
6 & 8 & $11 \cdot 8$ & $7 \cdot 44$ & $3 \cdot 6$ & $11 \cdot 2$ \\
Mean & 9 & $17 \cdot 7$ & $7 \cdot 40$ & $4 \cdot 8$ & 11.7 \\
SD & $1 \cdot 1$ & $8 \cdot 2$ & 0.04 & 0.7 & 0.5 \\
\hline
\end{tabular}

$\mathrm{f}=$ respiratory rate; $\mathrm{TV}=$ tidal volume; $\mathrm{PaCO}_{2}, \mathrm{PaO}_{2}=$ arterial carbon dioxide and oxygen tensions

attained by right hemidiaphragmatic stimulation $(0.86(0.37) \mathrm{kPa})$.

For bilateral and unilateral pacing there were no significant differences between the first PDI values recorded after implantation of the pacemaker and those at the last follow up visit which ranged from four to 45 months after starting electrophrenic pacing. Figure 2 shows the changes with time in PDI recorded with bilateral stimulation for each of the six subjects. Whilst there were quite large changes with time for some individuals, there was no consistent change with time for the group. No significant correlation was found between any PDI values and either the conduction speed or the diaphragmatic action potentials recorded before pacemaker insertion, nor was there any correlation found between the interval from the spinal injury to the commencement of pacing and either TV or PDI.

Table 2 shows the values for breathing frequency, TV, and arterial gases during electrophrenic pacing for each patient at their last follow up when they were considered to be in a stable and optimal state.

\section{Discussion}

Recovery of the diaphragmatic muscle fibres is the basis of the conditioning period following implantation of a pacemaker. ${ }^{616}$ The evolution of TV values suggests that after three months, when the conditioning period is ended, TV values become relatively stable. This sequence of improvement probably reflects the time needed for all diaphragmatic fibres to recover from the disuse atrophy that occurs in the months of mechanical ventilation after spinal injury. However, we found no correlation between either TV or PDI and the time lapse between the accident that produced the quadriplegia and implantation of the pacemaker.

The pacing parameters and rate of progression during the conditioning phase were based on clinical observations of each patient's tolerance of pacing and spirometric measurements made during the conditioning period; these parameters are simple and immediately perceptible. PDI measurements are more complex and troublesome to make and cannot be repeated frequently. We found that PDI values did not correlate well with the evolution of TV and, for this reason, we no longer include PDI in the routine follow up methods for the conditioning period. The fact that diaphragmatic pacing could be maintained for prolonged periods of time allowed the possibility of diaphragmatic muscle fatigue to be excluded. ${ }^{17-19}$

The PDI values obtained in this study were slightly lower than those reported in studies of other types of patients. Aubier et $a l^{17}{ }^{19}$ studied muscular fatigue in non-quadriplegic subjects using supramaximal transcutaneous and puncture stimulation and obtained values of $3 \cdot 14$ and $3.27 \mathrm{kPa}$. Hubmayr et $\mathrm{al}^{20}$ studied the influence of thoracoabdominal morphology on diaphragmatic pressure and obtained a value of $3 \cdot 1 \mathrm{kPa}$. In a group of patients with quadriplegia Glenn et $a l^{2}$ found similar PDI values at the beginning of the conditioning period and higher PDI values at the end of it.

PDI after bilateral stimulation was always superior to that elicited by unilateral stimulation. Bilateral contraction is always more effective than unilateral contraction ${ }^{21}$ because contraction of a single hemidiaphragm can be accompanied by paradoxical movement of the other hemidiaphragm and because muscle shortening depends on the distensibility of the opposite hemidiaphragm. With regard to unilateral contraction, the PDI generated by left hemidiaphragm pacing is generally greater than 
that produced by right, and Bellemare $e t a l^{2}$ noted these differences in 1986. Although the abdomen is conceptualised traditionally as a liquid-filled container, it has been shown in $\mathrm{dogs}^{23}$ that there may be considerable regional differences in the pressures recorded during spontaneous breathing, mechanical ventilation, abdominal compression, or diaphragmatic pacing. The gastric balloon is placed beneath the left diaphragm and pressure variations may be absorbed on the other side by the liver, or the right diaphragm is less susceptible to paradox because of the liver and so the left gives best TV.

PDI varied only slightly throughout the observation period, from 1.1 to $2.5 \mathrm{kPa}$, and no tendency was seen toward a steady increase. PDI is the result of a combination of two relatively independent variables: (1) recovery of the diaphragmatic muscular fibres after a period of disuse after spinal injury, and (2) the diaphragmatic pacing regimen which depends on the increase in TV sought and patient tolerance. On the other hand, TV is influenced by other factors apart from PDI, ${ }^{24}$ one of which is the paradoxical inward movement of the chest wall above the contracting diaphragm as a result of uncoordinated contraction of accessory respiratory muscles. ${ }^{25}$ No significant correlation was found between concurrent PDI and TV values; however, in cases 1 and 2, in whom the largest improvement in TV was seen, PDI in fact decreased slightly. In all the other cases there was an initial increase in TV with PDI remaining unchanged. These findings strongly suggest that in the first two cases the improvement in TV was, at least in part, due to improvement of the mechanical characteristics of the respiratory system.

We conclude that it is possible to successfully change quadriplegic patients from mechanical ventilation to electrophrenic pacing and to maintain satisfactory ventilation with an improved quality of life. During the three months or so of conditioning the TV increased progressively but not thereafter, whereas the PDI did not change significantly at all. We therefore recommend that only TV measurement and patient tolerance are used in the management of the conditioning period when commencing electrophrenic pacing.
1 Glenn WWL, Hogan JF, Phelps ML. Ventilatory support of the quadriplegic patient with respiratory paralysis by
diaphragm pacing. Surg Clin North Am 1980;60:1055-78. diaphragm pacing. Surg Clin North Am 1980;60:1055-78.
2 Glenn WWL, Hogan JF, Loke JS, Phelps ML. Ventilatory support by pacing of the conditioned diaphragm in quadriplegia. N Engl f Med 1984;310:1150-5

3 Garrido H, Mazaira J, Gutiérrez P, Madrazo J, Rivas J, González E. Continuous respiratory support in quadriplegic children by bilateral phrenic nerve stimulation. Thorax 1987;42:573-7.

4 Glenn WW, Brouillette RT, Dentz B, Fodstad H, Hunt CE, Keens TG, et al. Fundamental considerations in pacing of the diaphragm for chronic ventilatory insufficiency; a multi-center study Pace 1988;11:2121-7.

5 Hunt CE, Brouillette RT, Weese-Mayer DE, Morrow A, llwabi MN. Diaphragm pacing in infants and children. Pace 1988; 11:2135-41.

6 Garrido H, Arévalo JM, Pirla J, Vilches J, Aparicio J, Rivas $\mathrm{J}$ et al. Alteraciones morfoestructurales del nervio frénico y músculo diafragma tras electroestimulación con marcapasos diafragmático experimental. Cir Esp 1989;46:4719.

7 Newson Davis J. Phrenic nerve conduction in man. $f$ Neurol Neurosurg Psychiatr 1967;30:420-6.

8 Shaw RC, Glenn WWL, Hogan J, Phelps ML. Electrophysiological evaluation of phrenic nerve function in candidates for diaphragm pacing. $\mathcal{F}$ Neurology 1980;53:34554.

9 McKenzie DK, Gandevia SC. Phrenic nerve conduction times and twitch pressures of the human diaphragm. $f$ Appl Physiol 1985;59:1496-504.

10 Talonen PP, Baer GA, Häkkinen V, Ojala JK. Neurophysiological and technical considerations for the design of an implantable phrenic nerve stimulator. Med Biol Eng Comput 1990;28:31-7.

11 Salmons S. Importance of the adaptative properties of skeletal muscle in long-term electrophrenic stimulation of the diaphragm. Stereotact Funct Neurosurg 1989;53:223.

12 Baer GA, Talonen PP, Häkkinen V, Exner G, Yrjöla H. Phrenic nerve stimulation in tetraplegia. Scand $\mathcal{f}$ Rehab Med 1990;22:107-11.

13 Kirby RR, Banner MJ, Downs JB. Clinical applications of ventilatory support. Oxford: Churchill Livingstone, 1990.

14 Agostoni E, SantAmbrogio G, del Portillo Carrasco H. Electromyographic of the diaphragm in man and transdiaphragmatic pressure. F Appl Physiol 1986;61:1153-61.

15 Roussos CH, Macklem PT. Diaphragmatic fatigue in man. f Appl Physiol 977;43:189-97.

16 Salmoms S, Henriksson J. The adaptative response of skeletal muscle to increased use. Muscle Nerve 1981;4:94-105.

17 Aubier M, Farkas G, de Troyer R, Roussos C. Detection of diaphragmatic fatigue in man by phrenic stimulation. of Appl Physiol 1981;50:538-44.

18 Bellemare F, Grassino A. Evaluation of human diaphragm fatigue. F Appl Physiol 1982;53:1196-206.

19 Aubier M, Murciano D, Lecocguic Y, Viires N, Pariente R. Bilateral phrenic stimulation: a simple technique to assess diaphragmatic fatigue in humans. $\mathcal{F}$ Appl Physiol 1985;53 58-64.

20 Hubmayr RD, Litchy WJ, Gay PC, Nelson SB. Transdiaphragmatic twitch pressure: effects of lung volume and chest wall shape. Am Rev Respir Dis 1989;139:647-52.

21 Wilcox PG, Eisen A, Wiggs BJ, Pardy RL. Diaphragmatic relaxation rate after voluntary contractions and uni and bilateral phrenic stimulation. $\mathcal{F}$ Appl Physiol 1988;65:67582.

22 Bellemare F, Bigland-Ritchie B, Woods JJ. Contractile properties of the human diaphragm in vivo. $f$ Appl Physiol 1986;61:1153-61.

23 Decramer M, de Troyer A, Kelly S, Zocchi L, Macklem PT. Regional differences in abdominal pressure swings in dogs. F Appl Physiol 1984;57:1682-7.

24 Loh L, Goldman M, Newson Davis J. The assessment of diaphragmatic function. Medicine 1977;56:165-9.

25 Nochomowitz ML, Peterson DK, Stellato TA. Electrical activation of the diaphragm. Clin Chest Med 1988;9:34958 